\title{
Accuracy and Internal Fit of 3D printed Occlusal Splint, according to the printing position - A technique report
}

\author{
- Mayra Torres Vasques Department of Prosthodontics, School of Dentistry, University of São Paulo, São Paulo, SP, Brazil \\ - Dalva Cruz Laganá Department of Prosthodontics, School of Dentistry, University of São Paulo, São Paulo, SP, Brazil
}

ABSTRACT | Understanding the importance of 3D printing strategies is a key to obtain predictable, optimized and consistent dental appliances using digital technologies. This study aims to present the influence of printing orientation on the intraoral fit of full arch coverage splints. Splints were designed for two patients using the CAD software and printed in a SLA 3D printer with different orientations (o, 30, and 90 degrees), and the internal fit was checked on patients' mouth. Differences between the fit of the splints were verified, with the worst results for 900 oriented splints, although more detailed studies are recommended by the authors.

DESCRIPTORS | Three-Dimensional Printing; Accuracy; Dimensional Measurement; Occlusal Splint; Print Orientation.

RESUMO || Precisão e ajuste interno da placa oclusal impressa em 3D, de acordo com a posição de impressão - um relatório técnico - Compreender a importância de estratégias de impressão 3D é uma chave para obter aparelhos dentários estáveis, aperfeiçoados e consistentes utilizando tecnologias digitais. Este estudo tem como objetivo apresentar a influência da inclinação da impressão sobre a precisão do ajuste intraoral de placas de arco de cobertura total. As placas foram projetadas para dois pacientes com uso do software CAD e de uma impressora 3D SLA com diferentes inclinações (o, 30 e 90 graus), e o ajuste interno foi verificado na boca dos pacientes. Foi possível verificar diferenças entre o ajuste interno das placas, com os piores resultados para placas com inclinação de 90 graus, embora estudos mais detalhados sejam recomendados.

DESCRITORES | Impressão tridimensional; Precisão; Medição das dimensões; Placa oclusal; Inclinação da Impressão.

CORRESPONDING AUTHOR | • Mayra Torres Vasques Department of Prosthodontics, School of Dentistry, University of São Paulo • Avenida Prof. Lineu Prestes, 2227 São Paulo, SP, Brazil • 05508-000 E-mail:mtvasques@usp.br

- Received July 16, 2018 • Accepted August 30, 2018

- DOI http://dx.doi.org/10.11606/issn.2357-8041.clrd.2018.148012 


\section{INTRODUCTION}

One of the goals of modern Dentistry is to obtain predictable, optimized and consistent dental appliances using digital technologies. ${ }^{1}$ The advent of $3 \mathrm{D}$ printers based on additive manufacturing and the recent development of biocompatible resins for $3 \mathrm{D}$ printers for a long-term use allowed the development of intraoral appliances such as bite splints. According to Stansbury and Idacavage (2016) "there are projections that the dental market for additive manufacturing processes is prime for explosive future growth".

The stereolithography (SLA), commercially developed by 3D System Company in 1986, is one of the additive manufacturing processes to build incrementally by layers $3 \mathrm{D}$ objects through controlled ultraviolet laser light polymerization of photosensitive liquid resins. ${ }^{2}$

Considering the accuracy in printed intraoral appliance's fitting, one of the variables that must be considered is the influence of printing strategy. ${ }^{3}$ Focusing on the optimization of the printing area, some professionals use a vertical orientation $\left(90^{\circ}\right)$ of the splint models, despite recommendations of the resin manufacturer to position the objects with maximum inclination of $30^{\circ} .4^{4}$

The models' orientations have already been the focus of a study evaluating the accuracy of a printed dental crown according to nine different positions, which found significant differences on the accuracy of the crowns. ${ }^{5}$

This technique study was conducted to verify the influence of the orientation of the objects during the print in the final internal adjustment of full arch coverage splints.

\section{TECHNICAL REPORT}

To proceed with the experiment, a splint based on the patient's digital models (intraorally scanned) was designed using the computer-aided design (CAD) software (Meshmixer $\AA$ - Autodesk, San Rafael, CA, USA) - Figure 1, and the designed model was exported in a stereolithographic file (STL).

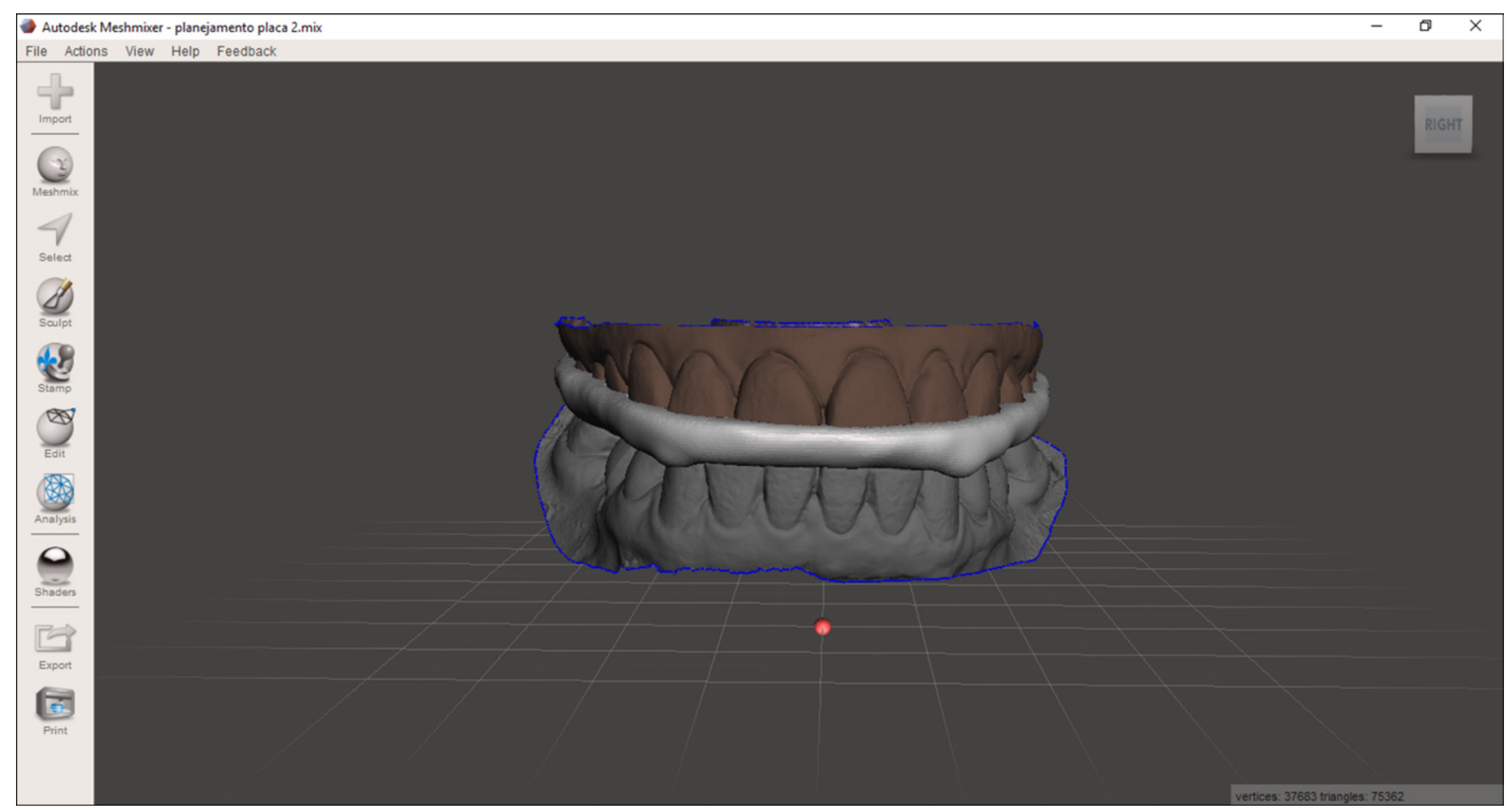

FIGURE 1 | Splint Design on Meshmixer CAD Software. 
To position and process the image's slices to be printed, the software Preform (Formlabs, Somerville, Massachusetts, USA) was used; the same STL file was opened and positioned in the center of the build platform with angles of 0,30 and 90 degrees each print time, considering the occlusal surface (Figures 2a, 2b, and 2c).
To print the splints, the SLA 3D Printer Form2 (Formlabs, Somerville, Massachusetts, USA) was used with the biocompatible, class II long-term use resin Clear LT® (manufactured by Vertex-Dental B.V; The Netherlands. to Formlabs - Somerville, MA, USA) (Figure 3).
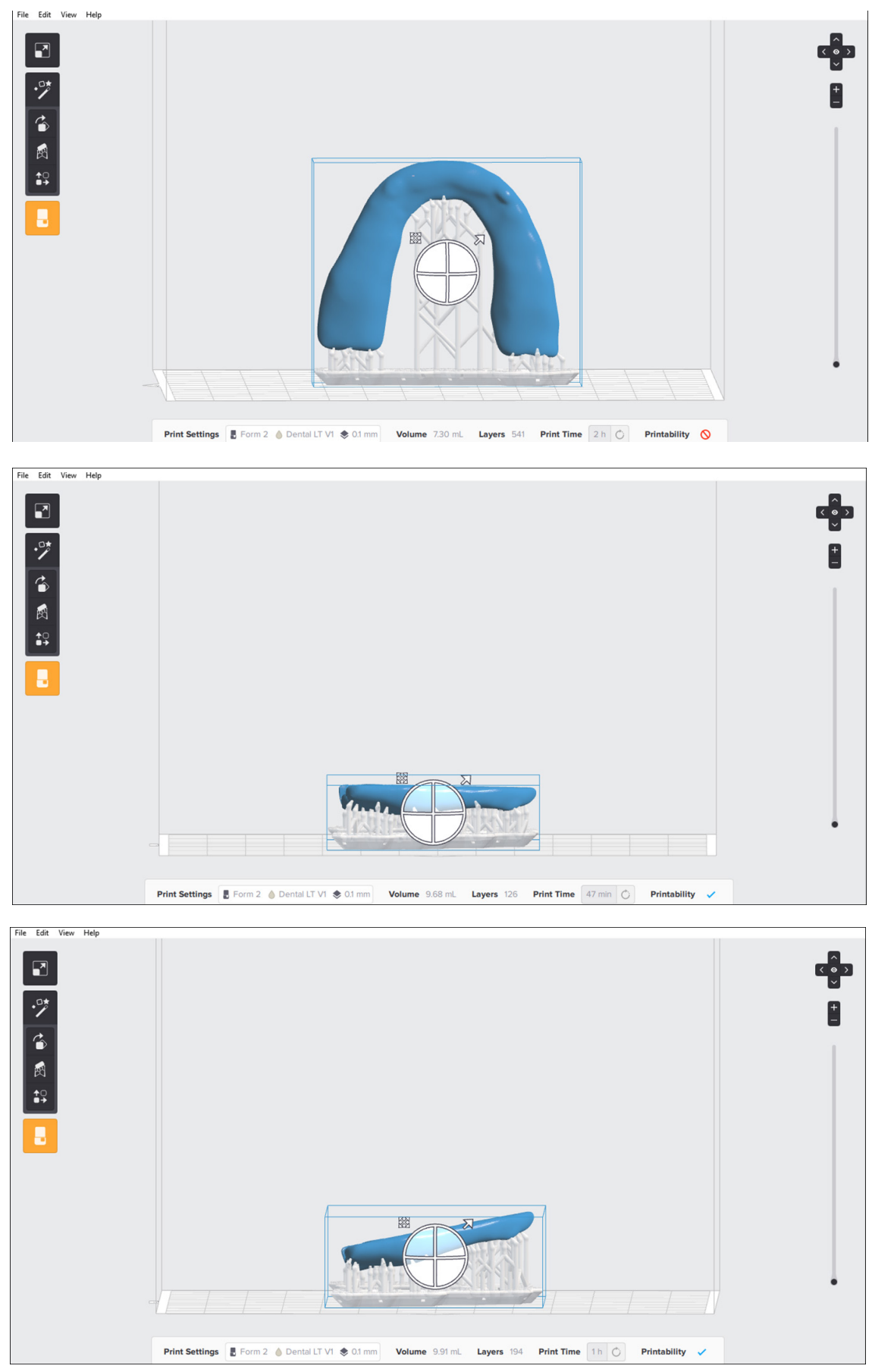

Figure 2a, 2b and 2c | Planning the Printing Position of the Splints on Preform Software ( $\mathrm{a}$ - 0 degree, $\mathrm{b}$ - 30 degree, c 90 degree). 


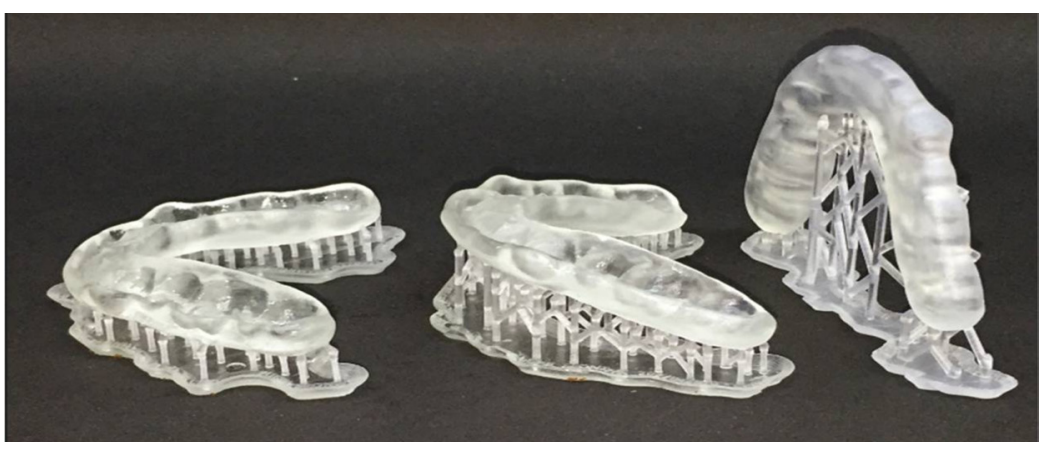

FIGURE 3 | Printed Splints with Supports (0, 30 and 90 degrees orientated on pinter, from left to right).
The printed appliance was post-processed following the manufacturer's recommendations; the uncured resin excess was removed using isopropyl alcohol in an ultrasonic cube (first alcohol bath for 3 minutes followed by a new alcohol bath for 2 minutes), the internal surface was brushed in the bath and the printed object was dried. Before removing the supports, a final cure was performed using an ultraviolet (UV) light chamber for 20 minutes $(405 \mathrm{~nm}, 36 \mathrm{~W})$, heated at $80^{\circ} \mathrm{C}$.
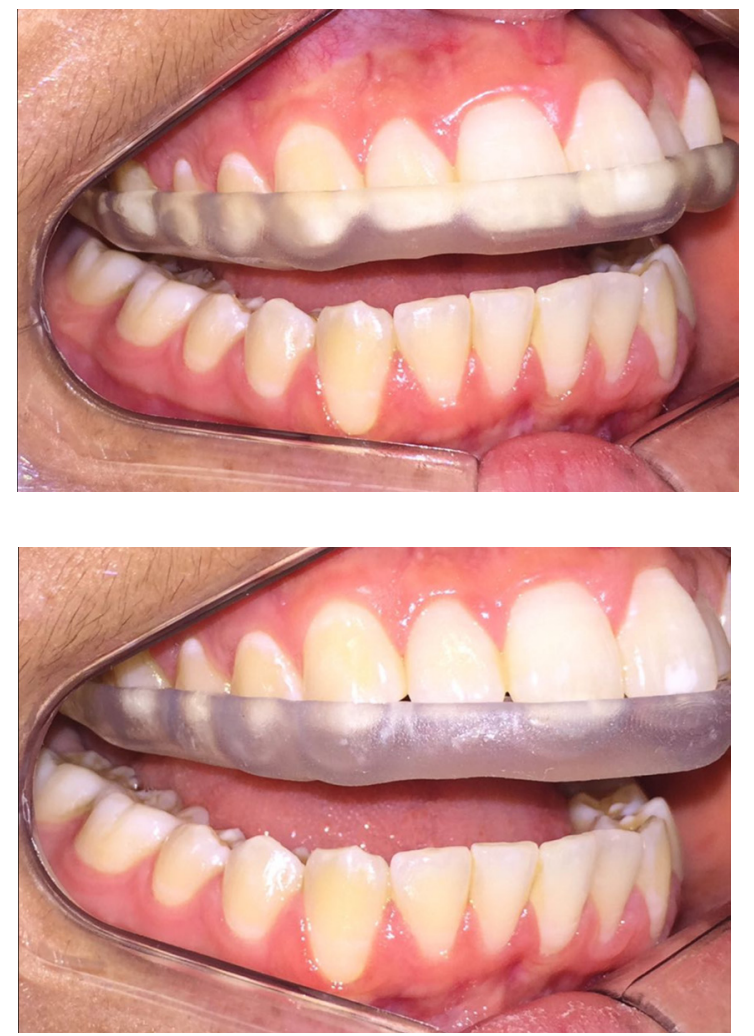

To the final shape of the appliances, the supports were removed and an adjustment of the occlusal surface was performed.

The appliances were tested in the patient's mouth $(\mathrm{n}=2)$ to check the fit. The $\mathrm{O}^{\circ}$ printed splint fitted properly, the splint printed at $30^{\circ}$ was close to fit, and the one printed at $90^{\circ}$ did not fit (Patient 1 - Figures 4a, 4b, and 4c; Patient 2 Figures 5a, 5b, and 5c, respectively).

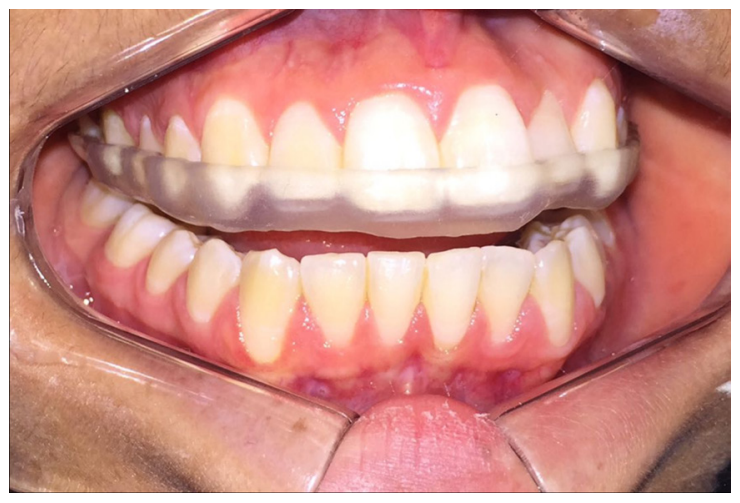

FIGURE 4a, 4b, 4c | Intraoral Splints Fit - Patient 1 $(0,30$ and 90 degrees orientated on pinter, a - 0 degree, $b$ 30 degree, $\mathrm{c}-90$ degree). 

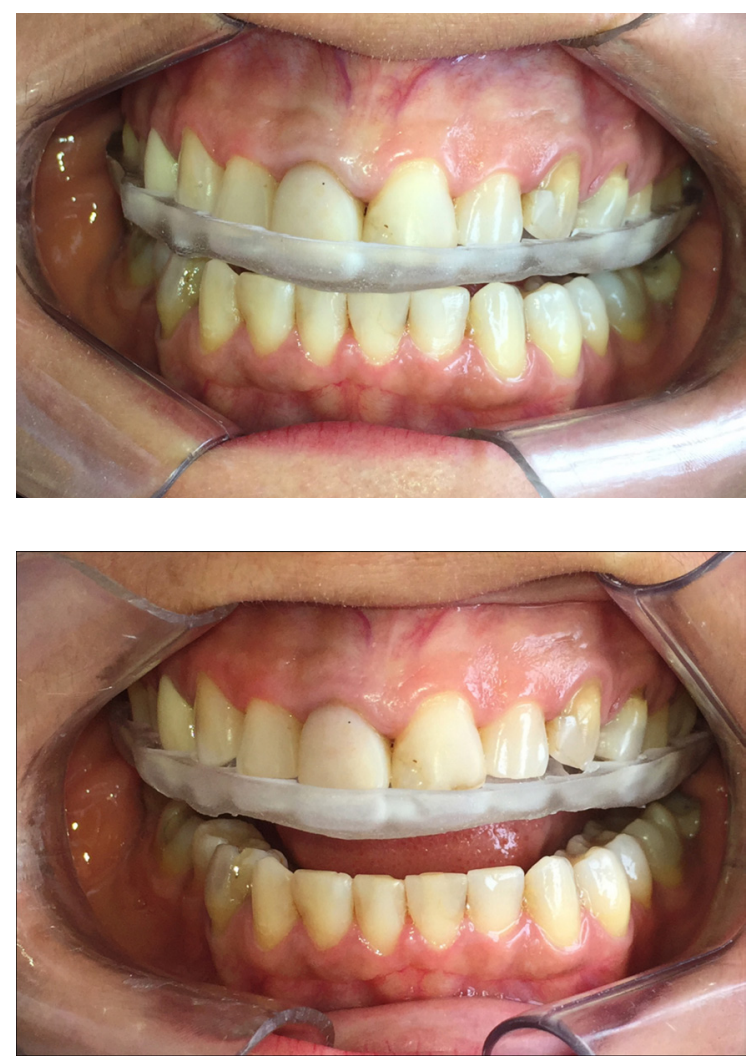

This study is part of a research approved by the Research Ethics Committee of the School of Dentistry of the University of Sao Paulo (protocol number - 48318215.8.0000.0075).

\section{DISCUSSION}

The current growth of the use of $3 \mathrm{D}$ technology in Dentistry has generated concerns about the best conduct to obtain the best performance of the equipment and the resins used, focusing on reliable and accurate appliances production.

Lots of studies verify the $3 \mathrm{D}$ image acquisition accuracy using scanners for lab and intraoral scanners, ${ }^{6}$ and others compare the differences between plaster dental models and printed dental models. ${ }^{7}$ Also, a few studies show the importance of the CAD design in the accuracy of the printed object. ${ }^{5}$

Recently, the emergence of the new biocompatible long-term resins creates the need for understanding the printer operation to

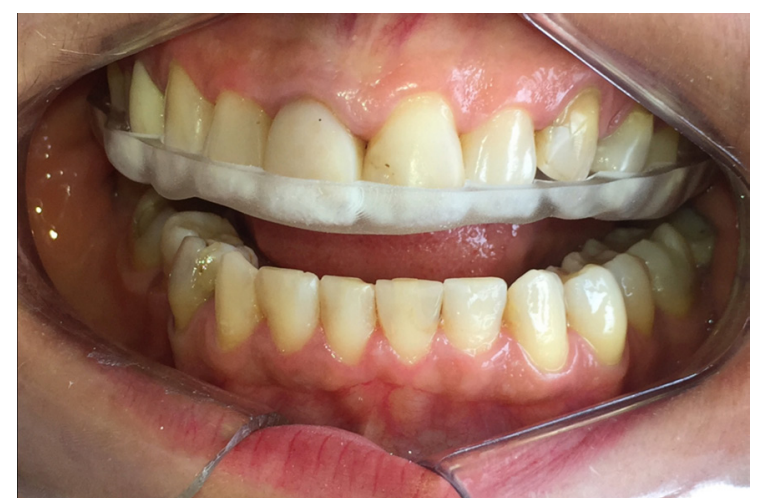

FIGURE 5a, 5b, 5c | Intraoral Splints Fit - Patient 1 $(0,30$ and 90 degrees orientated on pinter, $a-0$ degree, $b-$ 30 degree, $c$ - 90 degree).

avoid inherent critical issues that could affect the accuracy results of intraoral appliances and prostheses.

Different types of additive printers have particular limitations that must be identified and then overcome. The SLA printer uses a focused laser beam to polymerize precisely a resin area corresponding to the layer of the object. Angulations and insufficient supports can lead to minimal errors that are not acceptable in Dentistry, in which an accurate precision is necessaire; a micrometric variation can be the difference between the success and the failure. ${ }^{5}$

The perception that the position of the object on the building platform of the printer could be an important factor related to the accuracy is recent, it was first evaluated by engineers when designing mechanical gears. ${ }^{3}$ In Dentistry, the clinical observation of unexpected accuracy variations is bringing this topic into discussion, however, more 
studies to a better understanding of the problems and of how they could be faced are necessary.

\section{CONCLUSION}

Verifying that model printing orientation is determinant for the internal fit of the occlusal appliances was possible, despite this study has not performed any accuracy lab trial that could precisely determine the differences between the samples.

More studies with different orientations, different tests, and a bigger sample are recommended by the authors.

\section{ACKNOWLEDGMENT}

The first author would like to acknowledge CAPES (Coordenação de Aperfeiçoamento de Pessoal de Nível Superior) for the scholarship.

Conflict of Interest: The authors declare no conflict of interest.

\section{REFERENCES}

1. Dawood A, Marti Marti B, Sauret-Jackson V, Darwood A. 3D printing in dentistry. Br Dent J. 2015 Dec;219(11):521-9.

2. Stansbury JW, Idacavagec MJ. 3D printing with polymers: challenges among expanding options and opportunities. Dent Mat. 2016;32(1):54-64.

3. Leutenecker-Twelsiek B, Klahn C, Meboldt M. Considering part orientation in design for additive manufacturing. Procedia CIRP. 2016;50:408-13.

4. Formlabs. 3D Printing Splints with the Form 2. 2017 Oct. Available from: https://bit.ly/2wOX $5 \mathrm{RY}$

5. Alharbi N, Osman RB, Wismeijer D. Factors influencing the dimensional accuracy of $3 \mathrm{D}$-Printed Full-coverage dental restorations using stereolithography technology. Int J Prosthodont. 2016;29:503-10.

6. Goracci C, Franchi L, Vichi A, Ferrari M. Accuracy, reliability, and efficiency of intraoral scanners for full-arch impressions: a systematic review of the clinical evidence. Eur J Orthop. 2016;38(4):422-8.

7. Aragon MLC, Pontes LF, Bichara LM, Flores-Mir C, Normando D. Validity and reliability of intraoral scanners compared to conventional gypsum models measurements: a systematic review. Eur J Orthop. 2016;38(4):429-34. 